\title{
Description of the ARM Operational Objective Analysis System
}

June 2001

Minghua Zhang

State University of New York at Stony Brook, New York

Shaocheng Xie

Richard T. Cederwall

J. John Yio

Lawrence Livermore National Laboratory, Livermore, California

Work supported by the U.S. Department of Energy, Office of Science, Office of Biological and Environmental Research 


\section{Contents}

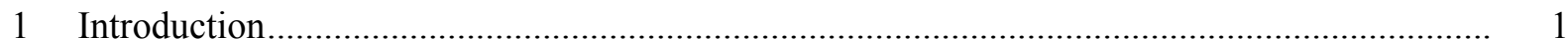

2 Overview of the Constrained Variational Analysis Method ................................................. 1

2.1 Theoretical Formulation................................................................................ 1

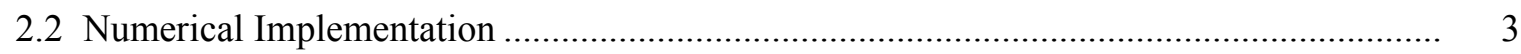

3 The Architecture of the ARM Operational Objective Analysis System ................................. 5

3.1 Preparation of the Required Raw Input Data ................................................................ 6

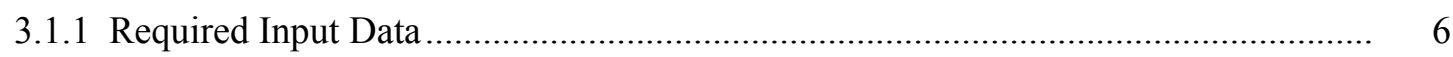

3.1.2 Files for Preparing the Raw Input Data ................................................................... 8

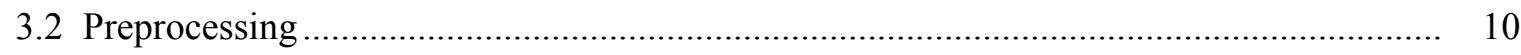

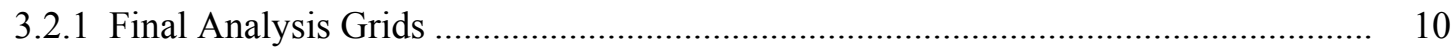

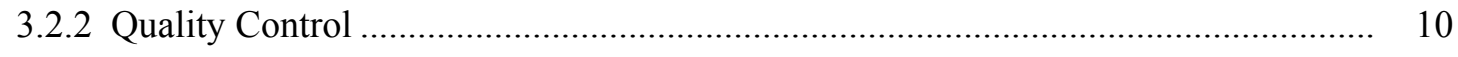

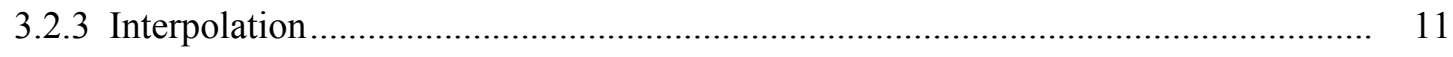

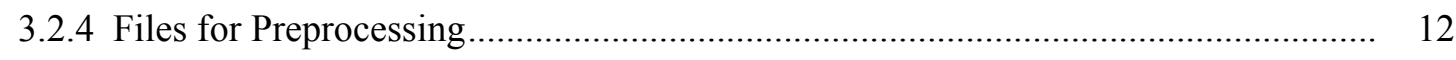

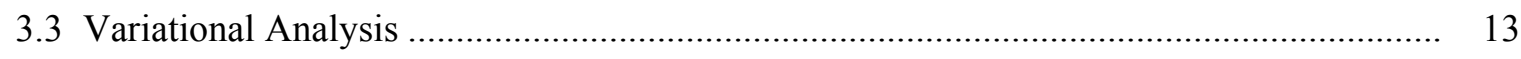

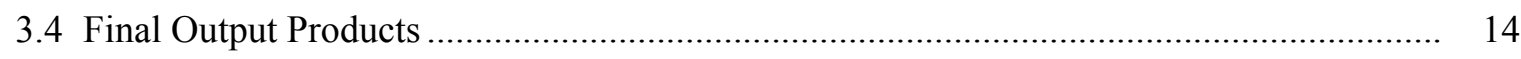

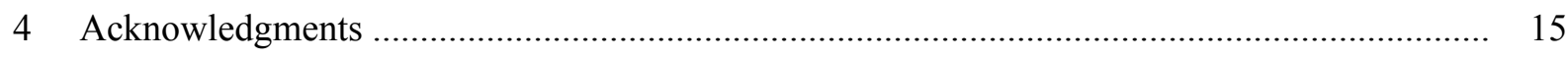

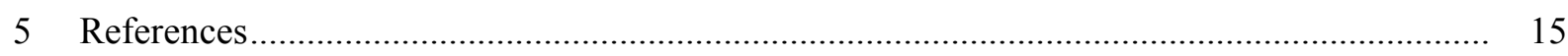




\section{Figures}

1 Illustration of the structure of the objective analysis system. ................................................. 6

2 Locations of the ARM upper-air data streams and the analysis grid points. ........................... 7

3 ARM surface data streams and GOES grids over the analysis domain. ................................ 8

\section{Tables}

1 File for preparation of the required raw input data ........................................................... 8

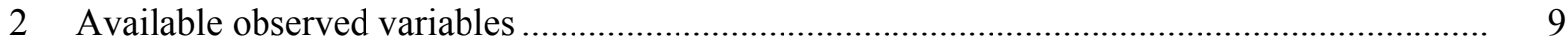

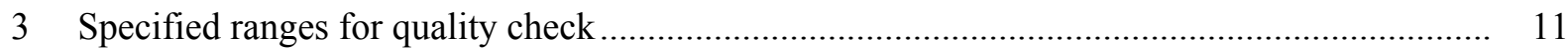

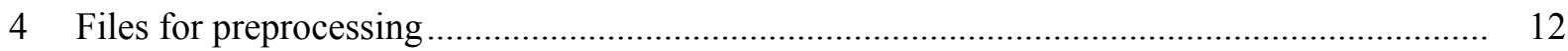

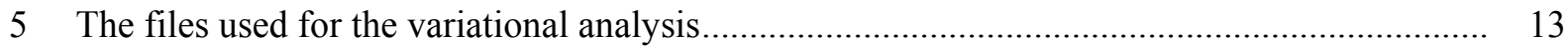




\section{Introduction}

This report describes the Atmospheric Radiation Measurement (ARM) operational variational objective analysis system. It is currently used to process data collected from the ARM intensive operational periods (IOPs) for driving and evaluating physical parameterizations in climate models. The analysis system was originally developed by Zhang and Lin (1997) at the State University of New York (SUNY) at Stony Brook and was migrated to the Lawrence Livermore National Laboratory (LLNL) as the ARM operational objective analysis system in May 1999. In contrast with previous objective analysis (e.g., Barnes 1964; O'Brien 1970; Lin and Johnson 1994) the ARM objective analysis used the constrained variational analysis method in which the atmospheric state variables are forced to satisfy the conservation of mass, heat, moisture, and momentum. The purpose of this technical report is to provide an overview of the constrained variational analysis method, the architecture of the objective analysis system, along with in-depth information on running the variational analysis codes.

\section{Overview of the Constrained Variational Analysis Method}

The constrained variational analysis method was developed by Zhang and Lin (1997) for deriving large-scale vertical velocity and advective tendencies from sounding measurements. It is used to process atmospheric soundings of winds, temperature, and water vapor mixing ratio over a network of a small number of stations. Given the inevitable uncertainties in the original data, the basic idea in this objective analysis approach is to adjust these atmospheric state variables by the smallest possible amount to conserve column-integrated mass, moisture, static energy, and momentum. Here, we will briefly review the approach. More details can be found in Zhang and Lin (1997) and Zhang et al. (2001).

\subsection{Theoretical Formulation}

From Zhang and Lin (1997), the governing equations of the large-scale atmospheric fields are:

$$
\begin{gathered}
\frac{\partial \overrightarrow{\mathrm{V}}}{\partial \mathrm{t}}+\overrightarrow{\mathrm{V}} \cdot \nabla \overrightarrow{\mathrm{V}}+\omega \frac{\partial \overrightarrow{\mathrm{V}}}{\partial \mathrm{p}}+\mathrm{f} \overrightarrow{\mathrm{K}} \times \overrightarrow{\mathrm{V}}+\nabla \phi=-\overline{\nabla \cdot\left(\overrightarrow{\mathrm{V}}^{\prime} \overrightarrow{\mathrm{V}}^{\prime}\right)}-\frac{\overline{\partial \omega^{\prime} \overrightarrow{\mathrm{V}}^{\prime}}}{\partial \mathrm{p}} \\
\frac{\partial \mathrm{s}}{\partial \mathrm{t}}+\overrightarrow{\mathrm{V}} \cdot \nabla \mathrm{s}+\omega \frac{\partial \mathrm{s}}{\partial \mathrm{p}}=\operatorname{Qrad}+\mathrm{L}(\mathrm{C}-\mathrm{E})-\overline{\nabla \cdot\left(\overrightarrow{\mathrm{V}}^{\prime} \mathrm{s}^{\prime}\right)}-\frac{\overline{\partial \omega^{\prime} \mathrm{s}^{\prime}}}{\partial \mathrm{p}}+\mathrm{L} \frac{\partial \mathrm{q}_{1}}{\partial \mathrm{t}} \\
\frac{\partial \mathrm{q}}{\partial \mathrm{t}}+\overrightarrow{\mathrm{V}} \cdot \nabla \mathrm{q}+\omega \frac{\partial \mathrm{q}}{\partial \mathrm{p}}=\mathrm{E}-\mathrm{C}-\overline{\nabla \cdot\left(\overrightarrow{\mathrm{V}}^{\prime} \mathrm{q}^{\prime}\right)}-\frac{\overline{\partial \omega^{\prime} \mathrm{q}^{\prime}}}{\partial \mathrm{p}}-\frac{\partial \mathrm{q}_{1}}{\partial \mathrm{t}} \\
\frac{\partial \omega}{\partial \mathrm{p}}+\nabla \cdot \overrightarrow{\mathrm{V}}=0
\end{gathered}
$$

with boundary conditions 


$$
\left.\omega\right|_{\mathrm{p}=\mathrm{p}_{\mathrm{s}}}=\frac{\partial \mathrm{p}_{\mathrm{s}}}{\partial \mathrm{t}}+\overrightarrow{\mathrm{Vs}} \cdot \nabla \mathrm{p}_{\mathrm{s}}
$$

and

$$
\left.\omega\right|_{\mathrm{p}=\mathrm{p}_{0}}=0
$$

where $\vec{V}$ is the wind, $s=\mathrm{C}_{\mathrm{p}} \mathrm{T}+\mathrm{gz}$ is the dry static energy, $\mathrm{q}$ is the mixing ratio of water vapor, and $\mathrm{p}_{\mathrm{s}}$ is the surface pressure. Large-scale is also referred to as grid scale, defined as the size of a sounding array comprising several stations. Prime denotes unresolvable motions of the observational network. Here, $\mathrm{Q}_{\mathrm{rad}}$ is the net radiative heating rate, $\mathrm{C}$ is the condensation of water vapor to rainwater, $\mathrm{E}$ is the evaporation of rainwater, and $\mathrm{q}_{1}$ is the cloud liquid water content.

Phase changes associated with ice are neglected for simplicity. Vertical integration of the above equations yields the following constraints:

$$
\begin{gathered}
\langle\nabla \cdot \overrightarrow{\mathrm{V}}\rangle=-\frac{1}{\mathrm{~g}} \frac{\mathrm{dp}_{\mathrm{s}}}{\mathrm{dt}} \\
\left.\frac{\partial<\mathrm{q}>}{\partial \mathrm{t}}+<\nabla \cdot \overrightarrow{\mathrm{V}} \mathrm{q}\right\rangle=\mathrm{E}_{\mathrm{s}}-\mathrm{P}_{\mathrm{rec}}-\frac{\partial<\mathrm{q}_{1}>}{\partial \mathrm{t}}+\omega_{\mathrm{s}} \mathrm{q}_{\mathrm{s}} / \mathrm{g} \\
\left.\frac{\partial<\mathrm{s}>}{\partial \mathrm{t}}+<\nabla \cdot \overrightarrow{\mathrm{V}} \mathrm{s}\right\rangle=\mathrm{R}_{\mathrm{TOA}}-\mathrm{R}_{\mathrm{SRF}}+\mathrm{LP}_{\mathrm{rec}}+\mathrm{SH}+\mathrm{L} \frac{\partial<\mathrm{q}_{1}>}{\partial \mathrm{t}}+\omega_{\mathrm{s}} \mathrm{S}_{\mathrm{s}} / \mathrm{g} \\
\frac{\partial<\overrightarrow{\mathrm{V}}>}{\partial \mathrm{t}}+\left\langle\nabla \cdot \overrightarrow{\mathrm{V}} \overrightarrow{\mathrm{V}}>+\mathrm{f} \overrightarrow{\mathrm{K}} \times<\overrightarrow{\mathrm{V}}>+\nabla<\phi>=\vec{\tau}_{\mathrm{s}}\right.
\end{gathered}
$$

where

$$
<X>=\frac{1}{g} \int_{p_{t}}^{p_{s}}(X) d p
$$

where $\mathrm{R}$ is the net downward radiative flux at top-of-the-atmosphere (TOA) and at the surface (SRF), $\tau_{\mathrm{s}}$ is the surface wind stress, $\mathrm{P}_{\text {rec }}$ is precipitation, $\mathrm{L}$ is the latent heat of vaporization, $\mathrm{SH}$ is the sensible heat flux, $E_{s}$ is the surface evaporation, and $\mathrm{p}_{\mathrm{t}}$ is the TOA pressure. $\omega_{\mathrm{s}}, \mathrm{q}_{\mathrm{s}}$, and $\mathrm{s}_{\mathrm{s}}$ are the pressure vertical velocity, water vapor mixing ratio, and dry static energy at the surface. The terms related with the $\omega_{\mathrm{s}}$ are from the vertical integration of the three-dimensional divergence terms. Physically, they represent the change of column moisture and column energy purely due to the change of column mass.

In the constrained variational analysis method, the atmospheric variables $(\vec{V}, s, q)$ are forced to satisfy Eqs. (7) - (10) with minimum adjustments to direct sounding measurements. The final analysis product is derived by minimizing the cost function: 


$$
I(t)=\iiint_{p, x, y}\left[\alpha_{u}\left(u^{*}-u_{0}\right)^{2}+\alpha_{v}\left(v^{*}-v_{0}\right)^{2}+\alpha_{s}\left(s^{*}-s_{0}\right)^{2}+\alpha_{q}\left(q^{*}-q_{0}\right)^{2}\right] d x d y d p
$$

with Eqs. (7) - (10) as strong constraints, where superscript "*” denotes the analyzed data and subscript " 0 " denotes direct measurements and $\alpha$ is the weighting function related with error estimates in the initial analysis.

\subsection{Numerical Implementation}

For $\mathrm{N}$ stations in the sounding network, each with $\mathrm{K}$ layers, we use xik to denote a state variable at station $\mathrm{i}$ and layer $\mathrm{k}$, and use column vector $\mathrm{X}$ to denote variable $(\mathrm{u}, \mathrm{v}, \mathrm{s}, \mathrm{q})$ at all grids,

$$
\mathrm{XT}=(\mathrm{x} 11, \mathrm{x} 12, \ldots, \mathrm{x} 1 \mathrm{k}, \mathrm{x} 21, \ldots, \mathrm{xik}, \ldots, \mathrm{xNK})
$$

where superscript $\mathrm{T}$ means transpose. The cost function of (11) can be written as

$$
\begin{gathered}
\mathrm{I}(\mathrm{t})=\left(\mathrm{u}^{*}-\mathrm{u}_{0}\right){ }^{\mathrm{T}} \mathrm{Q}_{\mathrm{u}}\left(\mathrm{u}^{*}-\mathrm{u}_{0}\right)+\left(\mathrm{v}^{*}-\mathrm{v}_{0}\right){ }^{\mathrm{T}} \mathrm{Q}_{\mathrm{v}}\left(\mathrm{v}^{*}-\mathrm{v}_{0}\right)+\left(\mathrm{s}^{*}-\mathrm{s}_{0}\right){ }^{\mathrm{T}} \mathrm{Q}_{\mathrm{s}}\left(\mathrm{s}^{*}-\mathrm{s}_{0}\right)+ \\
\left(\mathrm{q}^{*}-\mathrm{q}_{0}\right)^{\mathrm{T}} \mathrm{Q}_{\mathrm{q}}\left(\mathrm{q}^{*}-\mathrm{q}_{0}\right)
\end{gathered}
$$

where $\mathrm{Q}$ is the weighting matrix related with error covariance of a variable. The analyzed data are subject to the strong constraints of Eqs. (7) - (10). They can be written in the discrete forms

$$
\begin{gathered}
\operatorname{Ap}_{\mathrm{s}}\left({\overrightarrow{\mathrm{V}_{\mathrm{ik}}}}^{*}\right)=\left(\frac{1}{\mathrm{~g}} \frac{\partial \mathrm{p}_{\mathrm{s}}}{\partial \mathrm{t}}\right) \mathrm{m}+\left\langle\left(\nabla \cdot \overrightarrow{\mathrm{V}}^{*}\right) \mathrm{m}>\mathrm{k}=0\right. \\
\operatorname{Aq}\left({\overrightarrow{\mathrm{V}_{\mathrm{ik}}}}^{*}, \mathrm{qik}^{*}\right)=<\left(\frac{\partial \mathrm{q}}{\partial \mathrm{t}}\right)_{\mathrm{m}}>_{\mathrm{k}}+<\left(\nabla \cdot \overrightarrow{\mathrm{V}}^{*} \mathrm{q}^{*}\right)_{\mathrm{m}}>_{\mathrm{k}}-\mathrm{E}_{\mathrm{s}}+\mathrm{P}_{\mathrm{rec}}+<\left(\frac{\partial \mathrm{q}_{1}}{\partial \mathrm{t}}\right)_{\mathrm{m}}>_{\mathrm{k}}=0 \\
\mathrm{~A}_{\mathrm{s}}\left({\overrightarrow{\mathrm{V}_{\mathrm{ik}}}}^{*}, \mathrm{~s}_{\mathrm{ik}}^{*}\right)=<\left(\frac{\partial \mathrm{s}}{\partial \mathrm{t}}\right)_{\mathrm{m}}>_{\mathrm{k}}+<\left(\nabla \cdot \overrightarrow{\mathrm{V}}^{*} \mathrm{~s}^{*}\right)_{\mathrm{m}}>_{\mathrm{k}}-\mathrm{R}_{\mathrm{TOA}}+ \\
\mathrm{A}_{\mathrm{v}}\left(\overrightarrow{\mathrm{V}}_{\mathrm{ik}}^{*}, \phi_{\mathrm{ik}}^{*}\right)=<\left(\frac{\partial \overrightarrow{\mathrm{V}}^{*}}{\partial \mathrm{t}}\right)_{\mathrm{m}}>_{\mathrm{k}}+<\left(\nabla \cdot \overrightarrow{\mathrm{V}}^{*} \overrightarrow{\mathrm{V}}^{*}\right)_{\mathrm{m}}>_{\mathrm{k}}+\mathrm{f} \overrightarrow{\mathrm{K}} \times<\left(\overrightarrow{\mathrm{V}}^{*}\right)_{\mathrm{m}}>_{\mathrm{k}} \\
+<\left(\nabla \phi^{*}\right)_{\mathrm{m}}>_{\mathrm{k}}-\tau_{\mathrm{s}}=0
\end{gathered}
$$

where 


$$
<\mathrm{X}>=\sum_{\mathrm{k}=1}^{\mathrm{k}=\mathrm{K}}\left(\mathrm{X}_{\mathrm{k}}\right) \Delta \mathrm{P}_{\mathrm{k}}
$$

and subscript $\mathrm{m}$ represents average over the area covered by the $\mathrm{N}$ stations. Geopotential height can be derived from the virtual temperature analysis using the hydrostatic balance

$$
\frac{\partial \phi^{*}}{\partial \mathrm{p}}=-\frac{\mathrm{RT}_{\mathrm{V}}^{*}}{\mathrm{P}}
$$

The variational equations (Euler-Lagrange equations) for the analyzed variables of $\mathrm{u}_{\mathrm{ik}}^{*}, \mathrm{v}_{\mathrm{ik}}^{*}, \mathrm{q}_{\mathrm{ik}}^{*}, \mathrm{~s}_{\mathrm{ik}}^{*}$ are:

$$
\frac{\partial \mathrm{I}(\mathrm{t})}{\partial \mathrm{x}_{\mathrm{ik}}^{*}}+\lambda_{1}(\mathrm{t}) \frac{\partial \mathrm{A}_{\mathrm{p}_{\mathrm{s}}}}{\partial \mathrm{x}_{\mathrm{ik}}^{*}}+\lambda_{2}(\mathrm{t}) \frac{\partial \mathrm{A}_{\mathrm{q}}}{\partial \mathrm{x}_{\mathrm{ik}}{ }^{*}}+\lambda_{3}(\mathrm{t}) \frac{\partial \mathrm{A}_{\mathrm{s}}}{\partial \mathrm{x}_{\mathrm{ik}}^{*}}+\lambda_{4}(\mathrm{t}) \frac{\partial \mathrm{A}_{\mathrm{u}}}{\partial \mathrm{x}_{\mathrm{ik}}^{*}}+\lambda_{5}(\mathrm{t}) \frac{\partial \mathrm{A}_{\mathrm{v}}}{\partial \mathrm{x}_{\mathrm{ik}}{ }^{*}}=0
$$

where $x_{i k}^{*}$ stands for any one of $u_{i k}^{*}, v_{i k}^{*}, q_{i k}^{*}, s_{i k}^{*}$. Here $\lambda i$ is the Lagrange multiplier. Each variable has $\mathrm{N} \times \mathrm{K}$ grids. With a total of four variables and five Lagrange multipliers, the total number of variables to calculate at any given time is $4 \times \mathrm{N} \times \mathrm{K}+5$. They are solved from the $4 \times \mathrm{N} \times \mathrm{K}$ equations in Eq. (19) and five equations in Eqs. (14) - (17).

We assume measurement errors at different locations and for different variables uncorrelated. The covariance matrix is then diagonal. The diagonal elements are the reciprocal of error variances $\sigma_{\mathrm{x}_{\mathrm{ik}}}^{2}$. Thus, Eq. (19) becomes

$$
2 \sigma_{\mathrm{x}_{\mathrm{ik}}}^{-2}\left(\mathrm{x}_{\mathrm{ik}}^{*}-\mathrm{x}_{0, \mathrm{ik}}\right)+\lambda_{1}(\mathrm{t}) \frac{\partial \mathrm{A}_{\mathrm{p}_{\mathrm{s}}}}{\partial \mathrm{x}_{\mathrm{ik}}^{*}}+\lambda_{2}(\mathrm{t}) \frac{\partial \mathrm{A}_{\mathrm{q}}}{\partial \mathrm{x}_{\mathrm{ik}}^{*}}+\lambda_{3}(\mathrm{t}) \frac{\partial \mathrm{A}_{\mathrm{s}}}{\partial \mathrm{x}_{\mathrm{ik}}^{*}}+\lambda_{4}(\mathrm{t}) \frac{\partial \mathrm{A}_{\mathrm{u}}}{\partial \mathrm{x}_{\mathrm{ik}}^{*}}+\lambda_{5}(\mathrm{t}) \frac{\partial \mathrm{A}_{\mathrm{v}}}{\partial \mathrm{x}_{\mathrm{ik}}^{*}}=0
$$

or

$$
\mathrm{x}_{\mathrm{ik}}^{*}=\mathrm{x}_{0, \mathrm{ik}}-\frac{\sigma_{\mathrm{x}_{\mathrm{jk}}}^{2}}{2}\left[\lambda_{1}(\mathrm{t}) \frac{\partial \mathrm{A}_{\mathrm{p}_{\mathrm{s}}}}{\partial \mathrm{x}_{\mathrm{ik}}^{*}}+\lambda_{2}(\mathrm{t}) \frac{\partial \mathrm{A}_{\mathrm{q}}}{\partial \mathrm{x}_{\mathrm{ik}}^{*}}+\lambda_{3}(\mathrm{t}) \frac{\partial \mathrm{A}_{\mathrm{s}}}{\partial \mathrm{x}_{\mathrm{ik}}^{*}}+\lambda_{4}(\mathrm{t}) \frac{\partial \mathrm{A}_{\mathrm{u}}}{\partial \mathrm{x}_{\mathrm{ik}}^{*}}+\lambda_{5}(\mathrm{t}) \frac{\partial \mathrm{A}_{\mathrm{v}}}{\partial \mathrm{x}_{\mathrm{ik}}^{*}}\right]
$$

Numerical calculation of Eq. (21) and Eqs. (14) - (17) is carried out in an iterative mode. The iteration, when described to a single time level, contains three steps. The first step is that the previous estimate or original measurements are used to calculate each partial derivative to xik on the right-hand side of Eq. (21) using the formulas in Eqs. (14) - (17). A general form of constraint in Eqs. (14) - (17) can be written as

$$
\mathrm{A}_{\mathrm{Y}}\left(\mathrm{x}_{\mathrm{ik}}^{*}, \mathrm{y}_{\mathrm{ik}}^{*}\right)=0
$$


In an iteration, it can be written as

$$
\mathrm{A}_{\mathrm{Y}}\left(\mathrm{x}_{\mathrm{ik}}^{(1)}, \mathrm{y}_{\mathrm{ik}}^{(1-1)}\right)=0
$$

where 1 denotes the iteration index. When Eq. (21) is written as

$$
x_{i k}^{(1)}=x_{0, i k}-\frac{\sigma_{x_{j k}}^{2}}{2} \sum_{i=1}^{5} \lambda_{i}(t) B_{i, x k}^{(1-1)}
$$

where ${ }^{B_{i, x k}^{(l-1)}}$ are the partial derivatives from the first step, substitution of Eq. (24) into Eq. (23) yield a linearized set of equations for $\lambda \mathrm{i}$. More specifically, the substitution gives

$$
A_{Y i}\left(x_{0, i k}-\frac{\sigma_{x_{j k}}^{2}}{2} \sum_{i=1}^{5} \lambda_{i}(t) B_{i, x k}^{(1-1)}, Y_{i k}^{(1-1)}\right)=0
$$

Because of the linearity of the above operator, it can be further written as:

$$
\mathrm{A}_{\mathrm{Y}}\left(\mathrm{x}_{0, i \mathrm{k}}, \mathrm{Y}_{\mathrm{ik}}^{(1-1)}\right)-\sum_{\mathrm{i}=1}^{5} \frac{\sigma_{\mathrm{x}_{\mathrm{jk}}}^{2}}{2} \lambda_{\mathrm{i}}(\mathrm{t}) \mathrm{A}_{\mathrm{Y}}\left(\mathrm{B}_{\mathrm{i}, \mathrm{x}_{\mathrm{ik}}}^{(1-1)}, \mathrm{Y}_{\mathrm{ik}}^{(1-1)}\right)=0
$$

This set of five equations for the five constraints (Aps, Aq, As, Au, Av) is used to solve for $\lambda$ i at any given time. This constitutes the second step in the iteration.

In the third step, the adjustments are calculated by using the newly obtained $\lambda i$ in Eq. (24). After that, the next iteration is performed.

Because the constraints Eqs. (14) - (17) contain time derivatives, the actual iteration is carried out simultaneously for all time levels in the field experiment.

\section{The Architecture of the ARM Operational Objective Analysis System}

This section provides the details of the implementation of the constrained variational analysis method. Some of them are also described in Zhang et al. (2001). It should be noted that the analysis system is currently designed to process the ARM single-column model (SCM) IOP data at the Southern Great Plains (SGP) site. Thus, some of the implementation methods described below need to be modified according to the actual available data streams and data quality when applied to other locations and/or time periods.

Figure 1 shows the structure of the objective analysis system. It consists of four steps to finish data analysis: (1) preparation of the required raw input data, (2) preprocessing, (3) variational analysis, and (4) output final products. In step (1), all the required data are collected and reorganized from raw datasets 
to output in a standard format for further analysis. Step (2) includes major quality control of the raw data, averaging the data to form large-scale quantities, filling in missing measurements, and interpolation to consistent observation times. In step (3), the large-scale variables ( $\mathrm{u}, \mathrm{v}, \mathrm{T}, \mathrm{q})$ are adjusted by the constrained variational analysis method and the large-scale advective tendencies and vertical velocity are calculated. Step (4) outputs the variables that will be used to force and evaluate SCMs and cloud resolving models (CRMs).

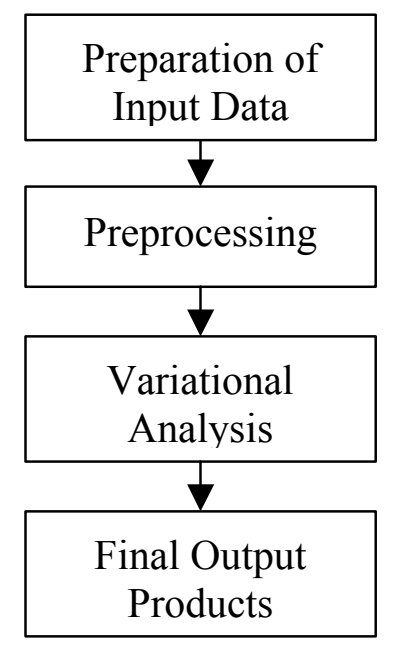

Figure 1. Illustration of the structure of the objective analysis system.

\subsection{Preparation of the Required Raw Input Data}

The following sections describe the required input data as well as the files used to process the raw data.

\subsubsection{Required Input Data}

The required input data include the large-scale state variables (u, v, T, q), surface measurements such as surface precipitation rates, surface sensible and latent heat fluxes, surface pressure, surface winds and temperature, surface broadband net radiative flux, net radiation at the TOA, and column total cloud liquid water. Currently, this analysis scheme only adjusts the large-scale state variables. The surface measurements and other data are used as the constraints for the variational analysis.

The large-scale state variables are from the ARM balloon-borne sounding and National Oceanic and Atmospheric Administration (NOAA) wind profiler measurements. There are five sounding stations at the SGP site: the central facility (C1) and four boundary facilities (B1, B4, B5, and B6) (Figure 2a). During the ARM SCM IOPs, sounding balloons are launched every three hours to measure the vertical profiles of temperature, water vapor mixing ratio, and winds. There are also 17 NOAA wind profiler stations near the SGP site (crosses in Figure 2c) taking hourly winds. It is seen from Figure $2 \mathrm{~b}$ that all five sounding stations actually overlap with the wind profilers. Around the SGP domain, there is a dense 

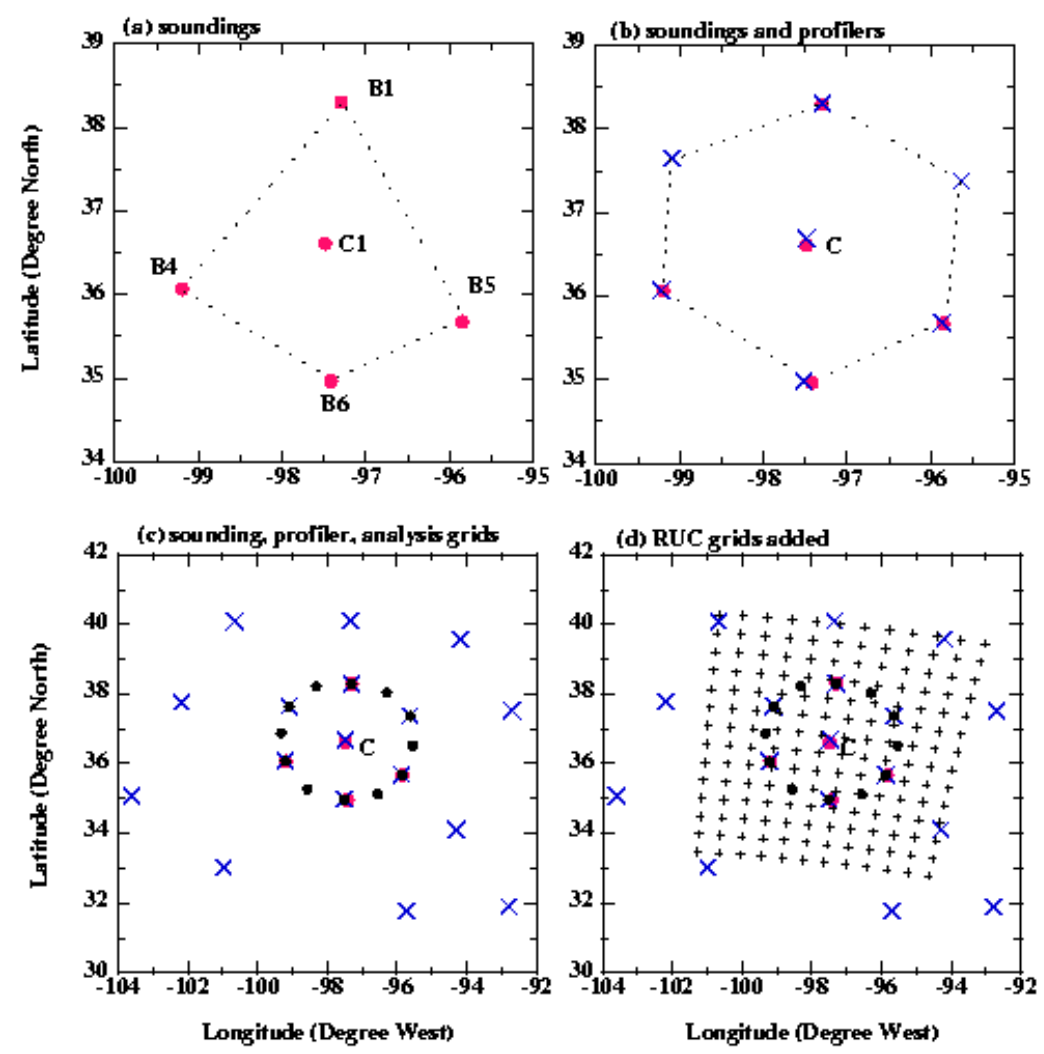

Figure 2. Locations of the ARM upper-air data streams and the analysis grid points:

(a) sounding stations, (b) 7 profiler stations (crosses), and (c) the 12 analysis grid points (heavy dots) in the hybrid approach. Also plotted are the nearby profiler stations (crosses). (d) RUC grids overlaid on other grids. (Adapted from Zhang et al. 2001)

surface measurement network at the ARM SGP site, along with satellite measurements from Geostationary Operational Environmental Satellite (GOES) (Figures 3a and 3b). These platforms include the following:

- Surface Meteorological Observation Stations (SMOS) measuring surface precipitation, surface pressure, surface winds, temperature, and relative humidity.

- Energy Budget Bowen Ratio (EBBR) stations measuring surface latent and sensible heat fluxes and surface broadband net radiative flux.

- Eddy Correlation Flux Measurement System (ECOR) providing in situ half-hour averages of the surface vertical fluxes of momentum, sensible heat flux, and latent heat flux.

- Oklahoma and Kansas mesonet stations (OKM and KAM) measuring surface precipitation, pressure, winds, and temperature. 
- Microwave Radiometer (MWR) stations measuring the column precipitable water and total cloud liquid water. Radar rainfall data are also available around the SGP domain during certain SCM IOPs. The satellite measurements of clouds and broadband radiative fluxes are available from the $0.5^{\circ} \times 0.5^{\circ}$ analysis of the GOES data (Minnis et al. 1995). In addition to these input data, the analysis system also requires operational analysis of the large-scale state variables from the NOAA mesoscale model Rapid Update Cycle (RUC) as the first guess. The RUC model grids are shown in Figure 2d. If some other data such as retrievals are available, they can be also easily included into the analysis system.
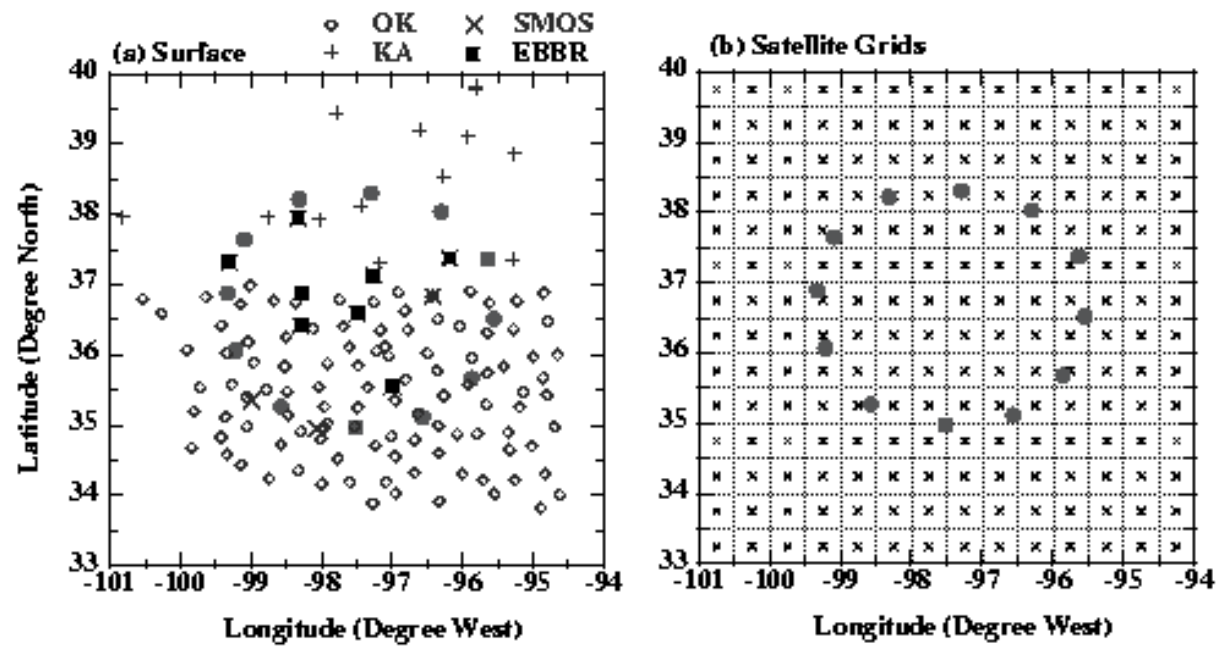

Figure 3. (a) ARM surface data streams (see text for complete instrument names) and (b) GOES grids over the analysis domain. (Adapted from Zhang et al. 2001)

\subsubsection{Files for Preparing the Raw Input Data}

Table 1 lists the files that are used to process the raw data in netCDF format from the ARM archive and output the required data in a standard ASCII format for further analysis. These codes are written in FORTRAN77. All missing data are set to -9999.0. Data from different instruments will keep their own observation times at this stage. The output files shown in the third column will be used as the input data for the next step analysis (preprocessing). The variables shown in the third column are described in Table 2.

\begin{tabular}{||l|l|l||}
\hline \multicolumn{2}{||c||}{ Table 1. File for preparation of the required raw input data. } \\
\hline \multicolumn{1}{|c|}{ Files } & \multicolumn{1}{c||}{ Function } & \multicolumn{1}{c||}{ Output } \\
\hline rsonde.for & Process sounding data & sonde.out: time, p, lon, lat, u, v, T, dew, RH, alt. \\
\hline rprofiler.for & Process wind profiler data & profiler_hour.out: time, lon, lat, alt, u, v. \\
\hline rruc.for & Process RUC data & ruc_model.out: time, p, Ps, alt, T, RH, u, v. \\
\hline rebbr.for & Process EBBR data & surf_ebbr.out: time, lon, lat, rads, Tsoil, lh, sh. \\
\hline recor.for & Process ECOR data & surf_ecor.out: time, lon, lat, alt, us, vs, ws, Tsair, lh, sh. \\
\hline rsmos.for & Process SMOS data & $\begin{array}{l}\text { surf_smos.out: time, lon, lat, alt, us, vs, Tsair, RHs, Ps, } \\
\text { prec. }\end{array}$ \\
\hline
\end{tabular}




\begin{tabular}{|l|l|l||}
\hline \multicolumn{2}{|l|}{ Table 1. Con't. } \\
\hline rkam.for & Process KAM data & surf_kam.out: time, lon, lat, prec, RHs, Tsair, us, vs. \\
\hline rokm.for & Process OKM data & surf_okm.out: time, lon, lat, prec, Ps, RHs, Tsair, us, vs. \\
\hline rmwr.for & Process MWR data & surf_mwr.out: time, lon, lat, vap, liq. \\
\hline rgoes.for & Process GOES data & $\begin{array}{l}\text { sat_goes.out: time, lon, lat, lwt, swt, lwt_clr, ins, swt_clr, } \\
\text { cld_low, cld_mid, cld_hgh, cld_tot, cld_top, cld_thick. }\end{array}$ \\
\hline rsiros.for & Process SIROS data & $\begin{array}{l}\text { surf_siros.out: time, lon, lat, lwsup, swsup, lwsdn, swsdn, } \\
\text { rads. }\end{array}$ \\
\hline
\end{tabular}

\begin{tabular}{|c|c|c|}
\hline Variables & Description & Instruments \\
\hline time $(*)$ & Julian day & All \\
\hline $\operatorname{lon}(*)$ & longitudes & All \\
\hline lat $(*)$ & latitudes & All \\
\hline $\mathrm{u}(\mathrm{m} / \mathrm{s})(*)$ & $\mathrm{x}$-component of horizontal wind & Sounding and wind profilers \\
\hline $\mathrm{v}(\mathrm{m} / \mathrm{s})(*)$ & y-component of horizontal wind & Sounding and wind profilers \\
\hline $\mathrm{T}(\mathrm{c})(*)$ & temperature profile & Sounding \\
\hline $\mathrm{RH}(\%)(*)$ & relative humidity profile & Sounding \\
\hline $\mathrm{p}(\mathrm{mb})(*)$ & pressure levels & Sounding \\
\hline $\operatorname{dew}(\mathrm{c})(*)$ & dewpoint temperature & Sounding \\
\hline alt $(\mathrm{m})(*)$ & altitude & Sounding, wind profilers, and SMOS \\
\hline $\operatorname{rads}(\mathrm{w} / \mathrm{m} 2)(*)$ & net surface radiation & EBBR and SIROS \\
\hline Tsoil ( c ) & soil temperature & EBBR \\
\hline $\operatorname{lh}(\mathrm{w} / \mathrm{m} 2)(*)$ & surface latent heat flux & EBBR, ECOR \\
\hline $\operatorname{sh}(\mathrm{w} / \mathrm{m} 2)(*)$ & surface sensible heat flux & EBBR, ECOR \\
\hline us, vs (m/s) (*) & surface horizontal winds & Sounding, SMOS, KAM, OKM, and ECOR \\
\hline $\mathrm{ws}(\mathrm{m} / \mathrm{s})(*)$ & surface vertical wind & ECOR \\
\hline Tsair ( c ) & surface air temperature & Sounding, SMOS, KAM, OKM, and ECOR \\
\hline RHs (\%) (*) & surface relative humidity & Sounding, SMOS, KAM, and OKM \\
\hline Ps $(\mathrm{mb})(*)$ & surface pressure & Sounding, SMOS, and OKM \\
\hline $\operatorname{prec}(\mathrm{mm} / \mathrm{hr})(*)$ & surface precipitation rate & SMOS, KAM, OKM, and ABRFC \\
\hline $\operatorname{vap}(\mathrm{cm})$ & column-integrated water vapor & MWR \\
\hline $\operatorname{liq}(\mathrm{cm})(*)$ & column-integrated liquid water & MWR \\
\hline $\operatorname{lwt}(\mathrm{w} / \mathrm{m} 2)(*)$ & TOA net longwave radiative flux & GOES \\
\hline $\mathrm{St}(\mathrm{w} / \mathrm{m} 2)(*)$ & TOA net shortwave radiate flux & GOES \\
\hline lwt clr (w/m2) & TOA net clear-sky longwave radiative flux & GOES \\
\hline swt_clr $(\mathrm{w} / \mathrm{m} 2)$ & TOA net clear-sky shortwave radiative flux & GOES \\
\hline cld_low $(\%)$ & low cloud amount & GOES \\
\hline cld_mid (\%) & mid cloud amount & GOES \\
\hline cld_hgh $(\%)$ & high cloud amount & GOES \\
\hline cld_tot $(\%)$ & total cloud amount & GOES \\
\hline cld thick $(\mathrm{km})$ & cloud thickness & GOES \\
\hline cld_top $(\mathrm{km})$ & cloud top & GOES \\
\hline ins $(\mathrm{w} / \mathrm{m} 2)$ & TOA solar insolation & GOES \\
\hline lwsup (w/m2) & surface upward longwave radiative flux & SIROS \\
\hline swsup (w/m2) & surface upward shortwave radiative flux & SIROS \\
\hline lwsdn (w/m2) & surface downward longwave radiative flux & SIROS \\
\hline $\operatorname{swsdn}(\mathrm{w} / \mathrm{m} 2)$ & surface downward shortwave radiative flux & SIROS \\
\hline
\end{tabular}




\subsection{Preprocessing}

Major quality control of the raw data is carried out in this step. Missing data will be filled and data will be averaged to form large-scale quantities. In the end, all upper air state variables $(\mathrm{u}, \mathrm{v}, \mathrm{T}$, and q) will be interpolated to the final analysis grids and all surface and TOA measurements will be interpolated to the $0.5^{\circ} \times 0.5^{\circ}$ grids within the analysis domain (see Figure $3 \mathrm{~b}$ ) at consistent analysis times. Results from this step will be used as input for the variational analysis.

\subsubsection{Final Analysis Grids}

Final analysis grids, as shown in Figure 2c (dark dots), consist of the five sounding stations, two profiler stations, and six auxiliary grids, which make the analysis domain more symmetric. It is selected to make better use of the hybrid method proposed by Zhang et al. (2001) to calculate the large-scale advective tendencies and vertical velocity. The hybrid method combines the strength of the regular grid method and the line integral method. In the hybrid method, observations are first interpolated onto these analysis grids and then a line-integral method is used in the end to derive the fluxes out of or into the analysis domain. This method has the following advantages: (1) The analysis grids are selected to be as close as possible to the original observational stations, so that an analysis grid is never far away from a measurement station. Since most analysis grid overlap with measurement stations, actual measurements at these grids, if available, will dominate the analysis. (2) The auxiliary grids are added to improve the linear assumption on the line segment at the boundary, making use of measurements that are not located at the domain boundary. (3) This method can also account for the drifting and the time delay of balloons at different stations, since these factors can be included in the interpolation schemes. More details are given in Zhang et al. (2001).

\subsubsection{Quality Control}

There are four quality control checks used to automatically screen both sounding and wind profiler data.

1. Maximum and minimum check. This procedure will reject those data whose values are larger than their maximum value or smaller than their minimum values. The first two rows in Table 3 show the maximum and minimum values specified for each variables.

2. Outlier check according to standard deviation. If data departures from the mean larger than four times standard deviation, the data is rejected.

3. Time variability check. The time variability check is similar to the Grubbs check, which is essentially a high order analysis of variance technique, to check for outliers in the observation, but without being too restrictive that we retain natural variability in the data. This method is applied with a sliding block of seven deviation scores. After each test, six of them remain and a new deviation score is added to the block. The Grubbs method is used to answer the question: whether this new score contributes an inordinate amount to the variance of the block, so that it ought be considered an outlier. If the answer is no, the score at the front of the block is dropped to make room for the next score to enter the block and be tested. If the answer is yes (an outlier), 
this outlier score is removed from the block immediately, and the preceding six remain unchanged for the next test. The maximum range for time variability is given in the third row in Table 3.

4. Height-space check with specified range. This is similar to step 3, instead for height-space check. The last row in Table 3 specifies the maximum range for height-space variability.

It should be noted that, in addition to these procedures, a careful visual check of all input data is still necessary.

Table 3. Specified ranges for quality check.

\begin{tabular}{|l|c|c|c|c|c|c|c|c||}
\hline & $\begin{array}{c}\text { Time } \\
(\mathbf{d a y})\end{array}$ & $\mathbf{p}(\mathbf{m b})$ & $\mathbf{u}(\mathbf{m} / \mathbf{s})$ & $\mathbf{v}(\mathbf{m} / \mathbf{s})$ & $\mathbf{T}(\mathbf{c})$ & $\mathbf{T d}(\mathbf{c})$ & $\mathbf{R H}(\mathbf{\%})$ & $\mathbf{H}(\mathbf{m})$ \\
\hline Max. value & 367 & 1200 & 70 & 50 & 40 & 40 & 100 & 30000 \\
\hline Min. value & 0 & 0 & -50 & -50 & -90 & -100 & 0 & 0 \\
\hline Grubbs check in time & 1 & 3 & 3 & 3 & 3 & 3 & 10 & 100 \\
\hline $\begin{array}{l}\text { Grubbs check in height and } \\
\text { space }\end{array}$ & 0.2 & 8 & 3 & 3 & 3 & 3 & 10 & 150 \\
\hline
\end{tabular}

\subsubsection{Interpolation}

After the quality controls, the Cressman scheme (Cressman 1959) with a four-dimensional length scale of ( $50 \mathrm{~km}, 50 \mathrm{~km}, 50 \mathrm{mb}, 6$ hours) is used to interpolate the sounding and profiler data onto the final analysis grids. Iteration is carried out for three times. RUC analysis is used as the background. Since profiler winds are available only in height coordinate, atmospheric temperature and humidity (for the calculation of virtual temperature) are first analyzed using balloon soundings and RUC analysis at the profiler stations. Profiler wind measurements are then converted to pressure levels for subsequent analysis. Considering the temporal and spatial variability of the profiler winds that are less coherent than those from the sounding data, we used a half weight for the profiler data and full weight for the sounding data in the Cressman procedure.

All the constrained terms should be the area-averaged quantities within the analysis domain, since the advective transport terms only describe area-averaged quantities. To avoid biases of using overcrowding measurement stations in some areas, we lay the $0.5^{\circ} \times 0.5^{\circ} \mathrm{GOES}$ grids over the analysis domain (Figure $3 b$ ), and then derive the required quantities in each small grid box. If there are actual measurements within the subgrid box, simple arithmetic averaging is used to obtain the subgrid means. Some variables are available from several instruments as shown in Table 2 . They are merged in the arithmetic averaging process. In the process, we use a half weight for the data collected from the Oklahoma and Kansas mesonet stations and full weight for the sounding data and SMOS data. If there is no actual measurement in the small box, the Barnes scheme (Barnes 1964) is used with the length scale of (Lx $=$ $50 \mathrm{~km}, \mathrm{Ly}=50 \mathrm{~km}, \mathrm{Lt}=6$ hours) to fill the missing data. Domain averages of these quantities are obtained by using values from the $0.5^{\circ} \times 0.5^{\circ}$ grid boxes within the analysis domain. For surface rainfall, we will use radar rainfall data, instead of the data measured from OKM, KAM, and SMOS, whenever it is available. Details about the Cressman and Barnes schemes are described in Cressman (1959) and Barnes (1964), respectively. 


\subsubsection{Files for Preprocessing}

Table 4 lists the required files for preprocessing the raw data from step 1. The codes are written by IDL. These codes should be run in the order that is shown in Table 4. As mentioned earlier, for those variables that are available from several instruments, they are merged in the arithmetic averaging process.

It should be noted that the file sub.pro, which includes all required subroutines, must be run first before running those files in Table 4.

\begin{tabular}{|c|c|c|}
\hline Files & Function & Output \\
\hline itp 3d sq & Quality control for sounding data. (sonde.out) & sonde.di5 \\
\hline plot_sonde_missing & $\begin{array}{l}\text { Check missing data in original dataset and the data rejected } \\
\text { during the quality control procedure. }\end{array}$ & \\
\hline plot_rawsonde_visual & $\begin{array}{l}\text { Visual check sounding data after finishing the automatic } \\
\text { quality check in itp } \mathbf{3 d} \mathbf{s q} \text {. }\end{array}$ & \\
\hline itp_3d_pq & Quality control for wind profiler data. (profiler_hour.out) & Profiler_hour.di5 \\
\hline itp_3d_pq2 & $\begin{array}{l}\text { Same as itp_3d_pq except that it does 5-point moving } \\
\text { smooth for wind profiler data. This is recommended. }\end{array}$ & profiler_hour.di5_sm \\
\hline plot prof missing & Same as plot sonde missing except for wind profiler data & \\
\hline plot_rawprof_visual & $\begin{array}{l}\text { Same as plot_rawsonde_visual except for wind profiler } \\
\text { data }\end{array}$ & \\
\hline ipt_3d.pro & $\begin{array}{l}\text { Allow reading of the sounding, wind profiler, and RUC } \\
\text { data (sonde.out, profiler_hour.out, ruc_model.out) }\end{array}$ & \\
\hline ipt_3d1_loc & $\begin{array}{l}\text { Plot locations of the sounding and profiler stations, the } \\
\text { RUC model grids, and the final analysis grids. It requires } \\
\text { information about the locations. }\end{array}$ & \\
\hline itp_3d_ruc & $\begin{array}{l}\text { Interpolate RUC data onto the final analysis grids, sounding } \\
\text { grids, and wind profiler grids, respectively. } \\
\text { (ruc_model.out) }\end{array}$ & $\begin{array}{l}\text { ruc_model.agrid } \\
\text { ruc_model.prof } \\
\text { ruc_model.sonde } \\
\text { ruc_model.agrid_2d } \\
\text { ruc_model.prof_2d } \\
\text { ruc_model.sonde_2d }\end{array}$ \\
\hline plot_ruc_visual & $\begin{array}{l}\text { Same as plot_rawsonde_visual except for the interpolated } \\
\text { RUC data. }\end{array}$ & \\
\hline itp_3d_prof & $\begin{array}{l}\text { Convert wind profiler data from height coordinate to } \\
\text { pressure coordinate. Temperature and moisture from RUC } \\
\text { and sounding at the profiler stations are used to calculate } \\
\text { virtual temperature. (sonde.di5, profiler_hour.di5_sm, } \\
\text { ruc_model.prof, ruc_model.sonde, ruc_model.prof_2d, } \\
\text { ruc_model.sonde_2d) }\end{array}$ & ruc_prof.prof_tquv \\
\hline plot_prof_visual & $\begin{array}{l}\text { Same as plot_rawsonde_visual except for the new wind } \\
\text { profiler data in ruc_prof.prof tquv }\end{array}$ & \\
\hline itp_3d_final & $\begin{array}{l}\text { Interpolate sounding and wind profiler data onto the final } \\
\text { analysis grids. For wind fields, the sounding and wind } \\
\text { profiler data are merged with giving a half weight for the } \\
\text { wind profiler data and full weight for the sounding data. } \\
\text { (sonde.di5, ruc_prof.prof_tquv, ruc_model.agrid, } \\
\text { ruc_model.sonde, ruc_model.prof, ruc_model.agrid_2d, } \\
\text { ruc model.prof 2d, ruc model.sonde } \mathbf{2 d} \text { ) }\end{array}$ & $\begin{array}{l}\text { analysis.agrid_2d } \\
\text { analysis.agird }\end{array}$ \\
\hline
\end{tabular}




\begin{tabular}{|c|c|c|}
\hline Files & Function & Output \\
\hline plot_final_visual & $\begin{array}{l}\text { Same as plot_rawsonde_visual except for the data on the } \\
\text { final analysis grid. }\end{array}$ & \\
\hline ipt_ht & $\begin{array}{l}\text { Allow reading of all surface data collected from different } \\
\text { instruments (surf *.out and sonde.di5). }\end{array}$ & \\
\hline itp_ht_time & Set time coordinates for different IOPs. & \\
\hline itp_ht & Interpolate surface data onto the analysis time levels. & \\
\hline itp_ht_mask & $\begin{array}{l}\text { Reject suspicious data through visual check and output } \\
\text { required data for further analysis. }\end{array}$ & surf_*outn \\
\hline ipt_grid_2d & Allow reading of the GOES satellite data. (sat_goes.out) & \\
\hline itp_goes & $\begin{array}{l}\text { Interpolate the GOES satellite data onto the analysis time } \\
\text { levels. }\end{array}$ & sat_goes.outn \\
\hline ipt_2d & $\begin{array}{l}\text { Allow reading of the single layer data processed by itp_ht } \\
\text { and itp goes. (surf_*outn and sat_goes.outn) }\end{array}$ & \\
\hline ipt_2d-mix & Merge the header of the single layer data. & \\
\hline itp_2d & $\begin{array}{l}\text { Merge the single layer data and interpolate the data onto the } \\
0.5^{\circ} \times 0.5^{\circ} \text { grids within the analysis domain. }\end{array}$ & $\begin{array}{l}\text { grid_g.* } \\
\text { grid_ff** } \\
\text { grid_x. }\end{array}$ \\
\hline
\end{tabular}

\subsection{Variational Analysis}

As discussed in Section 2.2, numerical calculation of Eq. (21) and Eqs. (14) - (17) is carried out in an iterative mode. The number of iterations is set to 4 in current version. The weights in the cost function are determined by the uncertainties in the instruments and measurements. Zhang and Lin (1997) show that the uncertainties are $0.5 \mathrm{~m} / \mathrm{s}$ for winds, $0.2 \mathrm{~K}$ for temperature, and 3 percent of the specific humidity based on the estimates by the ARM instrument team. In addition, we also include a component that is related with the observed variance of atmospheric state variables in the sounding data. These standard deviations of the state variables are multiplied by a factor of 20 percent to account for aliasing errors; they are then added to the instrument and measurement estimates.

Table 5 lists the required files for the constrained variational analysis. These files are written in IDL and they should be run in the order that is shown in Table 5.

\begin{tabular}{|c|c|c|}
\hline Files & $\begin{array}{ll}\text { Function } \\
\end{array}$ & Output \\
\hline 3d_put & $\begin{array}{l}\text { Allow reading of the multi-layer data and using low pass filtering } \\
\text { method to filter the data in time, in pressure, and in space. } \\
\text { (analysis.agrid, sonde.di5, and grid_f.*) }\end{array}$ & \\
\hline 2d_put & $\begin{array}{l}\text { Allow reading of the single layer data at the } 0.5^{\circ} \times 0.5^{\circ} \text { grids and } \\
\text { averaging the data within the analysis domain. (grid_g.* and } \\
\text { grid_x.*) }\end{array}$ & \\
\hline budget_put & Set the budget constraints & \\
\hline assim & The main program to control the variational analysis & \\
\hline calc_budget_layer & Calculate budget terms & \\
\hline assimopt & $\begin{array}{l}\text { Output the variational analysis results, including the atmospheric } \\
\text { state variables and column budget for both before and after the } \\
\text { analysis. }\end{array}$ & $\begin{array}{l}\text { *.state } \\
\text { *.budget_layer } \\
\text { *.budget_column }\end{array}$ \\
\hline proc_output & Output the final analysis products & See section 3.4 . \\
\hline
\end{tabular}




\subsection{Final Output Products}

The final outputs from the variational analysis for the single-level time series and multi-layer data are listed below.

Single-level time series:

1. Julian day - Calday

2. year - Year

3. month - Month

4. day - Day

5. hour - Hour

6. minute - Minute

7. surface precipitation $-\operatorname{Prec}(\mathrm{mm} /$ hour $)$

8. surface latent heat flux - LH_(upward_W/m2)

9. surface sensible heat flux $-\overline{\mathrm{SH}} \_$(upward_W/m2)

10. domain averaged surface pressure - Area_Mean_Ps(mb)

11. surface pressure at the ARM central facility - Central_Facility_Ps(mb)

12. surface air temperature - Ts_Air(C)

13. ground temperature $-\mathrm{Tg}$ Soil $(\mathrm{C})$

14. surface air relative humidity - Sfc_Air_RH(\%)

15. averaged surface wind speed - Srf_wind_speed $(\mathrm{m} / \mathrm{s})$

16. surface $u$ wind $-u_{-}$wind_( $\left.\mathrm{m} / \mathrm{s}\right)$

17. surface $v$ wind $-v_{-} \_$wind $(\mathrm{m} / \mathrm{s})$

18. net downward radiation at the surface - Srf_Net_Dn_Rad(W/m2)

19. net upward radiation at the TOA - TOA_LW_Up $(\mathrm{W} / \mathrm{m} 2)$

20. net downward shortwave radiative at TOA - TOA_SW_Dn $(\mathrm{W} / \mathrm{m} 2)$

21. TOA insolation - TOA_Ins $(\mathrm{W} / \mathrm{m} 2)$

22. low cloud amount from GOES - GOES_Lowcld(\%)

23. middle cloud amount from GOES - GOES_Midcld(\%)

24. high cloud amount from GOES - GOES_Hghcld(\%)

25. total cloud amount from GOES - GOES_Totcld(\%)

26. cloud thickness from GOES - Cld_Thickness $(\mathrm{km})$

27. cloud top height from GOES - Cld_-Top_ht $(\mathrm{km})$

28. total cloud liquid water path from microwave radiometers - MWR_Cld_liquid(cm)

29. time change rate of precipitable water $-\mathrm{d}($ Column_H2O $) / \mathrm{dt} \_(\mathrm{mm} / \overline{\mathrm{h}} \text { our })$

30. column integrated horizontal transport of water vapor - Column_H2O_Advection_(mm/hour)

31. surface evaporation expressed in precipitation unit - Srf_Evaporation_(mm/hour)

32. time change of the column dry static energy - d(Column_Dry_Static_Energy)/dt_(W/m2)

33. column integrated horizontal advection of dry static energy Column_Dry_Static_Energy_Advection_(W/m2)

34. column integrated radiative heating - Column_Radiative_Heating_(W/m2)

35. column integrated net latent heating - Column_Latent_heating_(W/ $/ \mathrm{m} 2)$

36. pressure velocity at the surface - omega_surface_ $(\mathrm{mb} / \mathrm{hr})$

37. water vapor mixing ratio at the surface $-\mathrm{qs}$ _surface_ $(\mathrm{kg} / \mathrm{kg})$

38. dry static energy at the surface $-\mathrm{s} \_$surface_(K)

39. precipitable water from microwave radiometers - MWR_precip_water_(cm)

40. surface upward longwave radiation - Siros_Srf_LWUP_(W/m2) 
41. surface downward longwave radiation - Siros_Srf_LWDN_(W/m2)

42. surface upward shortwave radiation - Siros_Srf_SWUP_(W $/ \overline{\mathrm{W}} / \mathrm{m})$

43. surface downward shortwave radiation - Siros_Srf_SWDN_(W/m2)

Multi-Layer Fields of pressure-time cross sections:

1. pressure levels $-\mathrm{p} \_(\mathrm{mb})$

2. Julian day $-\mathrm{t}$ (day)

3. year - Year

4. month - Month

5. day - Day

6. hour - Hour

7. minute - Minute

8. air temperature - Temp_(K)

9. water vapor mixing ratio $-\mathrm{H} 2 \mathrm{O} \_$Mixing_Ratio_(g/kg)

10. $\mathrm{u}$ wind $-\mathrm{u}$ _wind_( $\mathrm{m} / \mathrm{s})$

11. v wind $-\mathrm{v}$ _wind_( $\mathrm{m} / \mathrm{s})$

12. pressure vertical velocity - omega_(mb/hour)

13. horizontal wind divergence - Wind_Div_(1/s)

14. horizontal temperature advective tendency - Horizontal_Temp_Advec_(K/hour)

15. vertical temperature advective tendency - Vertical_T_Advec(K/hour)

16. horizontal advective tendency of water vapor - Horizontal_q_Advec_(g/kg/hour)

17. vertical advective tendency of water vapor - Vertical_q_Advec $(\mathrm{g} / \mathrm{kg} / \mathrm{hour})$

18. dry static energy $-\mathrm{s}$ (Dry_Static_Energy)(K)

19. horizontal advective tendency of dry static energy - Horizontal_s_Advec_(K/hour)

20. vertical advective tendency of dry static energy - Vertical_s_A $\bar{d} \bar{e}$ ec(K/hour)

21. time change rate of dry static energy $-\mathrm{ds} / \mathrm{dt}(\mathrm{K} /$ hour $)$

22. time change rate of temperature $-\mathrm{DT} / \mathrm{dt}(\mathrm{K} /$ hour $)$

23. time change rate of water vapor mixing ratio $-\mathrm{dq} / \mathrm{dt} \_(\mathrm{g} / \mathrm{kg} / \mathrm{hour})$

24. apparent heating - Q1_(k/hour)

25. apparent water vapor $\overline{s i n k}-\mathrm{Q} 2$ _(K/hour $)$

26. cloud frequency (cloud amount) from Micro Pulse Lidar - cloud(\%).

\section{Acknowledgments}

This research was supported primarily under the U.S. Department of Energy's ARM Program. Work at SUNY Stony Brook was supported by ARM grant DE-FG02-98ER62570, and was also supported by the National Science Foundation under grant ATM9701950. Work at LLNL was performed under the auspices of the U.S. Department of Energy by the University of California, Lawrence Livermore National Laboratory under contract No. W-7405-Eng-48.

\section{References}

Barnes, S. L., 1964: A technique for maximizing details in numerical map analysis. J. Appl. Meteor., 3, 396-409.

Cressman, G. P., 1959: An operational objective analysis scheme. Mon. Wea. Rev., 87, 367-374. 
Lin, X., and R. H. Johnson, 1994: Heat and moisture budgets and circulation characteristics of a frontal squall line. J. Atmos. Sci., 51, 1661-1681.

Minnis, P., W. L. Smith, D. P. Garber, J. K. Ayers, and D. R. Doeling, 1995: Cloud properties derived from GOES-7 for spring 1994 ARM Intensive Observing Period using version 1.0.0 of ARM satellite data analysis program. NASA Ref. Publ. 1366, 59pp. (Available from NASA Langley Research Center, Technical Library, MS 185, Hampton, VA 23655-5225.)

O'Brien, J. J., 1970: Alternative solutions to the classical vertical velocity problem. J. Appl. Meteor., 9, 197-203.

Zhang, M. H., and J. L. Lin, 1997: Constrained variational analysis of sounding data bases on columnintegrated budgets of mass, heat, moisture, and momentum: Approach and application to ARM measurements. J. Atmos. Sci., 54, 1503-1524.

Zhang, M. H., J. L. Lin, R. T. Cederwall, J. J. Yio, and S. C. Xie, 2001: Objective analysis of ARM IOP Data: Method and sensitivity. Mon. Weather Rev., 129, 295-311. 